\title{
Towards interactive professional ethics
}

\section{IAN HARPER, ALBERTO CORSÍN JIMÉNEZ}

Ian Harper is Lecturer in Social Anthropology at the School of Social and Political Studies, University of Edinburgh. He is a member of the committee of the Association of Social of the Association of Socid
Anthropologists (ASA) responsible for the ethical guidelines and his email is iharper@staffmail.ed.ac.uk. Alberto Corsin Jiménez is Lecturer in the Anthropology of Organisations at the University of Manchester. He is the Media and Publicity Officer of the ASA. His email is alberto.corsin-jimenez@ manchesterac.uk.
Editorial note: This article should be read in conjunction with the debate between Devi Sridhar and Roderick Stirrat over ethics of development in relation to David Mosse's book on pp 17-19 of this issue.

\section{Ethics as defendable process}

Recent years have seen an upsurge of concern about ethics and ethical discourses. Anthropology, too, has developed an 'ethical anxiety' (Faubion 2003) and writings have proliferated around ethics in the discipline (Strathern 2000a, Caplan 2003a, Fluehr-Lobban 2004a, Meskell and Pels 2005), and ethics as more broadly conceived (Ong and Collier 2005). This broader concern has also been reflected in the concerns the Association of Social Anthropology (ASA) has with the development of the organization's own ethical guidelines, written as a professional code of conduct for the research process (see www.theasa.org). While most anthropological organizations are similarly concerned with ethical issues, here we focus specifically on the rationale behind the ASA's proposal to broaden the base from which its members relate to and engage with the ethical.

The current ASA ethical guidelines have done, and still do, a very good job of orienting researchers in the field, as well as providing them with institutional ethical clearance. Increasingly, however, there is a sense that the ethical guidelines need to embrace broader contemporary issues. The ethical challenges facing anthropology are no longer circumscribed - if they ever were - within the research process. Anthropology is today entangled in complex institutional and political structures which extend well beyond the dialogical relationships of fieldwork. The following comments relate to the urgent need to clarify the position of our discipline vis-à-vis the current intensification of focus on ethics in social discourse.

Whatever an ethics of anthropology might look like, the discipline finds that its ethical standards are frequently being judged by the standards of other disciplines. This is increasingly the case when guidelines are being developed in contexts where anthropology finds itself institutionally aligned with varying constellations of disciplines, depending on how anthropology departments have been farmed out into faculties or schools. This process of exteriorizing ethics, such that they become something external to the discipline and - increasingly - dealt with by committees, tends to lead to the codification of ethics and to ethical discourses of a legalistic and judicial kind (Pels 2005). It is also reminiscent of contemporary managerial practices, where professional judgment is displaced in favour of defendable process, and 'ethics' are operationalized as a sequence of control processes (Power 2004). In this context, ethics become less a quality of relationships than an aspect of managerial processes and outcomes.

One consequence of this has been an increasing focus on 'ethical fetishes' and a form of ethics that focuses on technical issues. An example might be how the achievement - or not - of informed consent has been fetishized at the expense of broader moral issues. Anthropologists have criticized this practice, and the way in which it both creates potentially demeaning relationships with our subjects of research and predetermines the research itself - where, for example, the 'information' involved in informed consent already places, and defines, subjects of research in a proto-proprietorial relationship with researchers (Strathern 2000b).

The tendency has also been for guidelines to focus on the research process and its methodological aspects, rather than the broader concern of anthropology as a field of critical enquiry. Research agendas and projects situate anthropolo- gists in particular relational worlds (with informants, with funders, with colleagues, etc.), but anthropologists may also be described as intellectuals, educators, teachers, consultants, critics - all modes of engagement with 'society' that can hardly be exhausted by regulations that focus on some aspects of the process at the expense of others. Yet in terms of our relations with others, focus on our research methodologies and the capacity to develop ethical fetishes such as informed consent is one of the main ways the discipline is judged. It is important, therefore, to resist this 'prescriptive description' of our discipline - to keep our own self-descriptions open and thereby stress the 'ethnographicness' of our own ethics (of which more below).

\section{Ethics beyond legalism}

The ASA, as the voluntary professional body for social anthropologists in the UK, is increasingly being asked to act as ethical adjudicator. For example, the ASA was recently asked to adjudicate in a debate over informed consent at a British university as a set of school-wide generic ethical guidelines were being developed. In this instance the anthropology department was in a school where it was teamed with psychology and sociology, and the restrictions imposed on students in terms of the stringent definition of informed consent made the practice of ethnography all but impossible. In another example, the ASA was approached in an attempt to prevent the publication of a book by David Mosse, some of the issues around which are discussed by Devi Sridhar and Roderick Stirrat (see pp. 17-19 in this issue). Some of Mosse's informants were concerned with the impact that the book might have had on their reputations (even jobs), and communicated their concerns to us. Having read the ASA ethical guidelines, they claimed that David Mosse had broken the first tenet of our own code, that of maintaining the anonymity of research subjects, and asked the association to take action.

This case indicates that the ASA is being asked to intervene in these situations in a quasi-legalistic way. This may be a reason for us to think carefully about how we position ourselves vis-à-vis our informants. However, we would like to suggest further that the robustness of an anthropological ethics should not be confined to consideration of the political relationships we have with our research subjects.

In this respect, we would like to add one other dimension to this timely discussion around the publication of David Mosse's book, and why we think we need more 'controversies' of this nature. When the ASA is asked to endorse particular accountability mechanisms, we should at the very least be aware that this comes within a context of institutional governance structures that delineate a very specific ethical field. When asked to endorse principles of accountability we are not just being asked to behave 'ethically'; we are being pushed to conform to one form of sociality (among many), defined explicitly by corporatecum-institutional concerns.

To limit the ethical to questions of professional reputation (be it that of our informants or our own) or to a breach of trust or responsibility is therefore only part of the story. The emerging debate around Mosse's book allows us to take ethics out of one frame (the Indo-British Rainfed Farming Project) and see how it holds up in another. Here is where a second ethnographic ethical moment emerges, which Mosse's monograph in fact also describes, and 

were first presented and discussed at a special session of the 2005 ASA conference, 'Engaging ethics: An open discussion on revising the ASA ethical guidelines', in April 2005. We thank those who attended the session for their comments. Thanks are also due to the ASA committee and to ANTHROPOLOGY TODAY' five anonymous reviewers for their comments on a first draft. Feedback welcome vi www.theasa.org/ethics.htm.

Battaglia, D. 1999. Toward an ethics of the open subject: Writing culture in good conscience. In: Moore, $\mathrm{H}$. L. (ed.) Anthropological theory today, pp. 114-150. Cambridge: Polity Press.

Borofsky, R. 2005. Yanomami: The fierce controversy and what we can learn from $i t$. Berkeley: University of California.

Caplan, P. (ed.) 2003a. The ethics of anthropology: Debates and dilemmas. London and New York: Routledge.

2003b. Introduction Anthropology and ethics. In: Caplan, P. (ed.) The ethics of anthropology: Debates and dilemmas,

pp. 1-33. London and New York: Routledge.

Cook, K.S. (ed.) 2003. Trust in society. New York: Russell Sage Foundation.

Faubion, J. 2003. Toward an anthropology of ethics: Foucault and the pedagogies of autopoiesis. In: Wyschogrod, E. \& McKenny, G. (eds) The ethical, pp. 145-165. Malden, MA: Blackwell Publishing.

Fluehr-Lobban, C. (ed.) 2004a. Ethics and the profession of anthropology: Dialogue for an ethically conscious practice.

2nd edn. Walnut Creek: Altamira Press.

2004b. Darkness in El Dorado: Research ethics, then and now. In: FluehrLobban, C. (ed.) Ethics and the profession of anthropology: Dialogue for an ethically conscious practice. 2nd edn, pp. 85-106. Walnut Creek: Altamira Press.

Marquand, D. 2004. The decline of the public: The hollowing out of citizenship. Cambridge: Polity Press.

Meskell, L \& Pels, P. (eds) 2005. Embedding ethics. Oxford \& New York: Berg.

Misztal, B.A 1996. Trust in modern societies: The search for the bases of social order. Cambridge: Polity Press.

O'Neill, O. 2002a. Autonom and trust in bioethics: The Gifford Lectures, University of Edinburgh 2001. Cambridge: Cambridge University Press. which it is hoped a broader debate will help map out further. Briefly, Mosse demonstrates ethnographically that the making of development is simultaneously embedded in, and envelops, the making of institutional ethics. In this perspective, inter-institutional conflict over the right to represent, say, expert or public knowledge, or what development is and/or does, turn out to be also about the politics that shape emerging assemblages of ethical concerns. Mosse's book appears in this light as a wonderfully rich - as well as sobering - account of some of the side-effects of the institutional managerialism of policy. As we argue below, this book, and the discussion it has stimulated, are thus reframing the terms of ethical engagement, seeking a path towards a form of ethnographic ethics. This is surely a much more suggestive model than an accounting model of pros and cons, or prescriptive lists of 'dos' and 'don'ts'.

We understand that for an increasing number of anthropologists - particularly those who find themselves in complex contemporary fields of research and 'studying up' - the current ASA guidelines don't offer much grounding to think through their research sites and issues. The practice of anthropology in certain contemporary institutional settings creates ever-shifting tensions between research, ethics and politics, which call for careful reconsiderations. In these contexts, forging responsible relationships can prove a formidable task, which is why the discipline needs a clearer sense of its own political position. As one reviewer of an earlier draft of this article put it: do we ask ourselves often enough fundamental questions about who and what anthropology is for, and whether there is a difference between this and our own ethical behaviour? We would answer that there is no difference, and that we need a better sense of what notions of, say, 'respect' or 'responsibility' might mean in practice - to both anthropologists and their subjects of research - under strained and asymmetrical institutional or political relations.

Furthermore, as some have pointed out in relation to the development of the American Anthropological Association (AAA) guidelines, such documents have tended to emerge at moments of crisis, the most recent being the TierneyChagnon affair (Fluehr-Lobban 2004b). Despite the AAA's resolve to establish guidelines that develop the conditions for an ethics that is more educational in focus than defensive, this tendency - turning to the formulation of ethical codes at moments of crisis - also results in the creation of forms of ethical codes that are legalistic, adjudicative and restrictive, an attempt to codify research behaviour in anticipation of legal challenge, and in those very terms.

Michael Power has recently observed that in this kind of defensive climate, "the traditional distinction between legal regulation, voluntary codes and organisation-specific rules is not useful; all are effectively experienced[...] "legalistically" and demand defensive compliance strategies.' Perhaps more significantly, when the legalistic takes over, professionals cease to speak on behalf of expert communities and become their own ethical risk managers instead (Power 2004: 47-48). It is in this context that ethics emerge as a hollow substitute in the face of the decline of the public (Marquand 2004). This is a dangerous development for our discipline. Our own domain of expertise is precisely 'the public', however defined, and to concede to the codification of ethics is therefore to concede to the privatization of social life, a parlous scenario for a discipline whose very core is the social.

\section{What should ethics do?}

So what do we want our ethical guidelines to do? And once decided, how do we achieve this? It is counterproductive to have our discipline develop ethical guidelines in a formal legalistic, defensive or precautionary way. Rather, our ethical guidelines should reflect an expression of the ethical commitment of the profession as a whole. We can hardly expect others to trust our public manifestation if we do not start by trusting it ourselves. However, trust works best not when it is institutionalized but when it is engaged and challenged (O’Neill 2002; cf. Cook 2003, Misztal 1996). Our ethics should therefore not be reactive (to crises) but should emerge from a sustained commitment of the discipline, and should be robust enough to deal with these situations. The guidelines should be continuously renewed as an ongoing project, rather than being subjected to sporadic updates by either individuals or committee.

Any application of these guidelines should not be about taking sides, but about thinking through and learning - an ethics that is predicated on the principle of its own selfactualization. As Caplan has remarked, ethics should also be 'intellectually holistic' - that is, relating to all aspects of the discipline: its epistemology, fieldwork practices, institutional and wider social contexts; and they should be politically conscious and aware of the political conditions under which our knowledge is produced - that is, reflexive and critical (Caplan 2003b). This is an ethics based on an awareness that the limits of any community of trust lie not in what it knows but in the courage to face up responsibly to what it does not know. This commitment to the possibility of ethical uncertainty could and should work both in relation to those who are positioned differently from us, but with whom we interact and may disagree over our practices and findings, and in relation to the uncertainty over what delineates the ethical field itself. In short, we need an anthropological ethics strong enough not to shy away from a politics of uncertainty (Power 2004; see also Battaglia 1999).

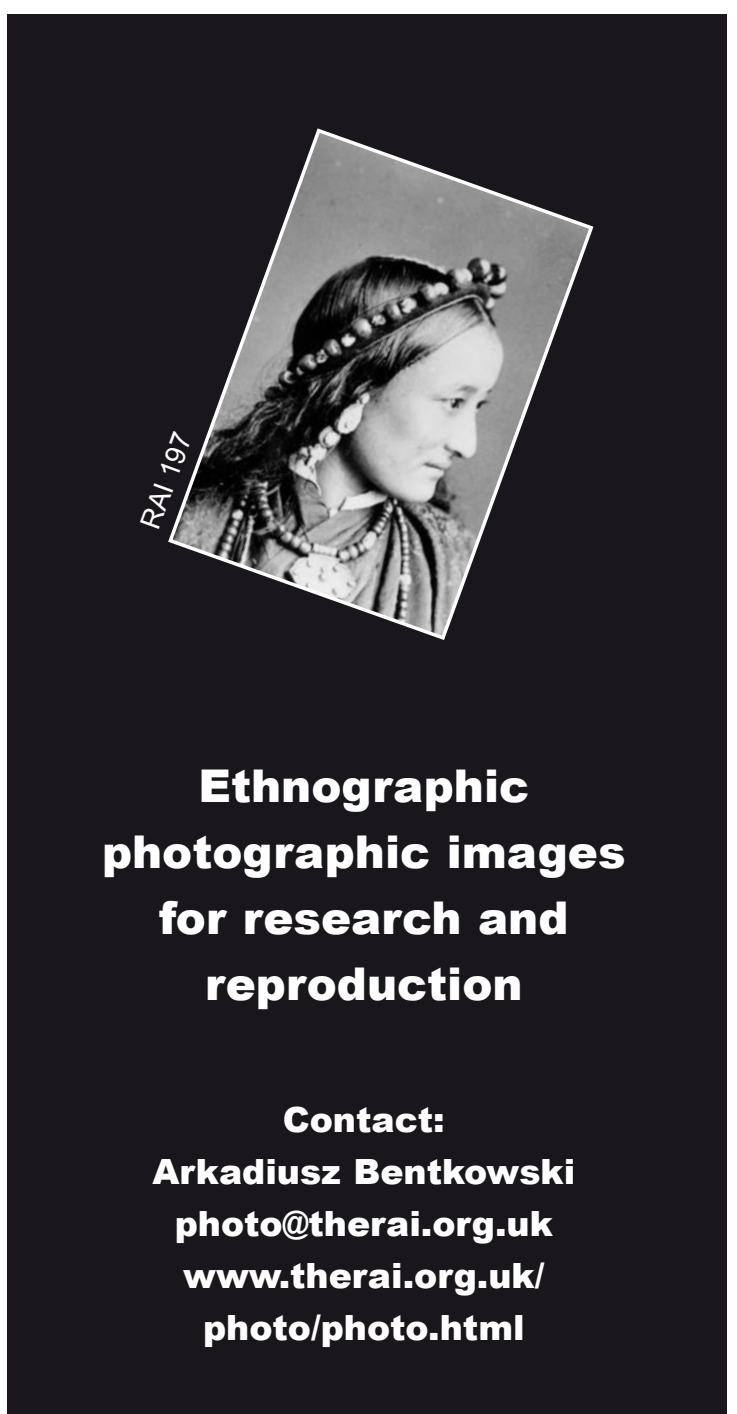




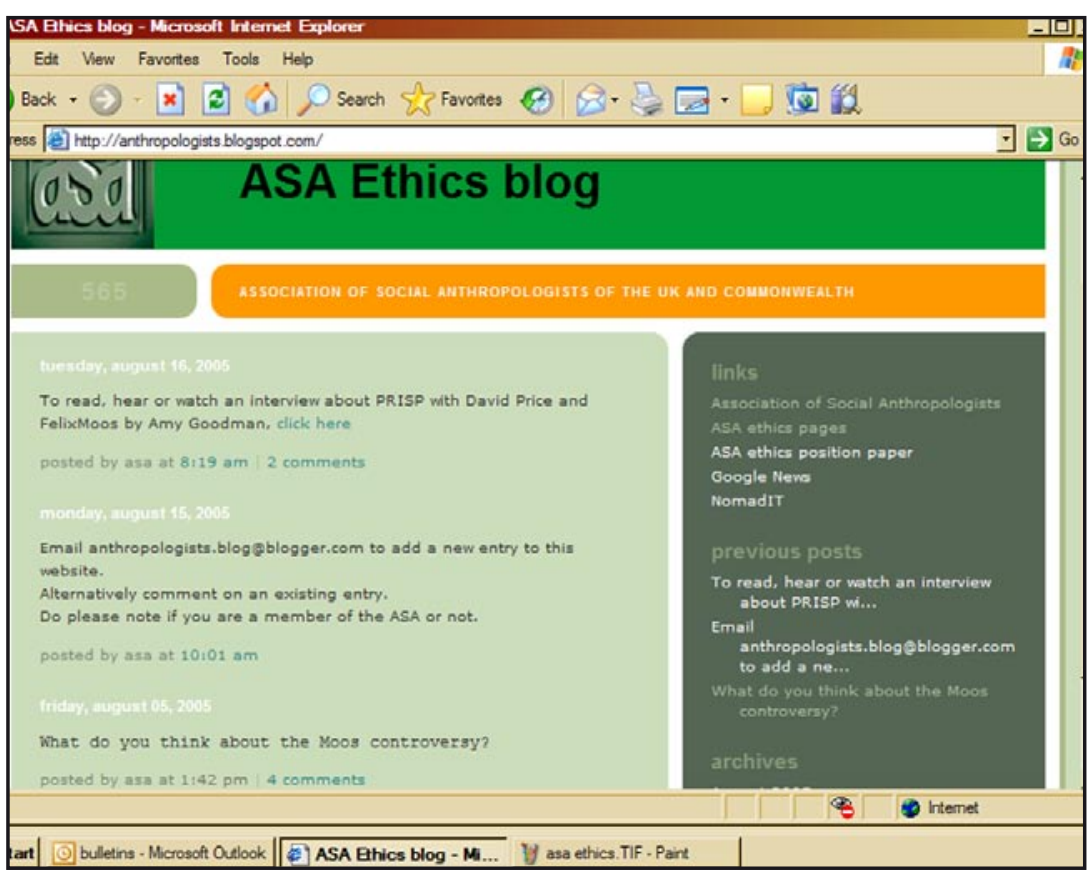

Figs 2 and 3. The

ASA ethics blog and

the ethics page on the

American Anthropological

Association website.

- 2002b. A question of trust: The BBC Reith Lectures 2002. Cambridge: Cambridge University Press.

Ong, A. \& Collier, S. (eds) 2005. Global assemblages: Technology, politics, and ethics as anthropological problems. Malden, MA: Blackwell Publishing.

Pels, P. 2005. 'Where

there ain't no ten commandments'

Redefining ethics during the Darkness in El Dorado scandal. In: Meskell, L. \& Pels, P. (eds) Embedding ethics, pp. 69-99. Oxford \& New York: Berg.

Power, M. 2004. The risk

management of everything. Rethinking the politics of uncertainty. London: Demos.

Salzano, F.M. \& Hurtado, A.M. (eds) 2004. Lost paradises and the ethics of research and publication. Oxford \& New York: Oxford University Press.

Strathern, M. (ed.)

2000a. Audit cultures:

Anthropological studies in accountability, ethics and the academy. London \& New York: Routledge.

2000b. Accountability and ethnography. In: Strathern, M. (ed.) Audit cultures: Anthropological studies in accountability, ethics and the academy, pp. 279-304. London \& New York: Routledge.

Tierney, P. 2000. Darkness in El Dorado: How scientists and journalists devastated the Amazon. New York: Norton.
The new communications opportunities offered by the internet now permit engagement with questions pertaining to professional ethics by all members of the profession (junior and senior), both amongst themselves and with the public. The recent debate involved in formulating, adopting and, eventually, rescinding the recommendations of the AAA's El Dorado Task Force report (first commissioned to investigate the allegations contained in Patrick Tierney's book Darkness in El Dorado) was all mediated by the internet in crucial ways (see Borofsky 2005, Salanzo \& Hurtado 2004, www.aaanet.org and www.publicanthropology.org for summaries and detailed discussion of issues). Not only was the initial concern about the book's implications for anthropology fuelled by forwarded emails and web-based speculation about its content and potential impact prior to its publication, but the AAA's response was also influenced and mediated by the internet. The AAA set up a task force to investigate Tierney's accusations, but the first report published on the internet was amended in response to the flood of comments to the AAA website (Borofsky 2005). Of these - and this is what Borofsky sees as grounds for the greatest hope for anthropology as a discipline in the US - 119 contributions were from students, against the 37 of professional anthropologists.

Under mounting pressure from critics who perceived the report as a whitewash, its contents were changed (ibid.). Following the subsequent referendum earlier this year, in which members voted to rescind the report, the AAA has launched an Online Comment Forum so that members can debate and discuss lessons learnt from the process (www. aaanet.org/press/an/0505/Referendum_Dialogue.htm). One of the major points being debated is whether the Task Force had the mandate and power to act as a legally binding tribunal.

\section{Ethics, ethnography and the internet}

The Association of Social Anthropologists also cannot slip into assuming that the organization has the mandate and power to act as a legally binding tribunal. In the search for the 'objective' we must be wary of self-serving defensive posturing, and need to open up what we do to 'the public analysis of divergent perspectives' (Borofsky 2005:18), a sentiment that David Mosse would echo in relation to his own work and his research subjects' right to object.

The internet appears today as the most obvious space for facilitating this. The ASA has therefore set up an interac-

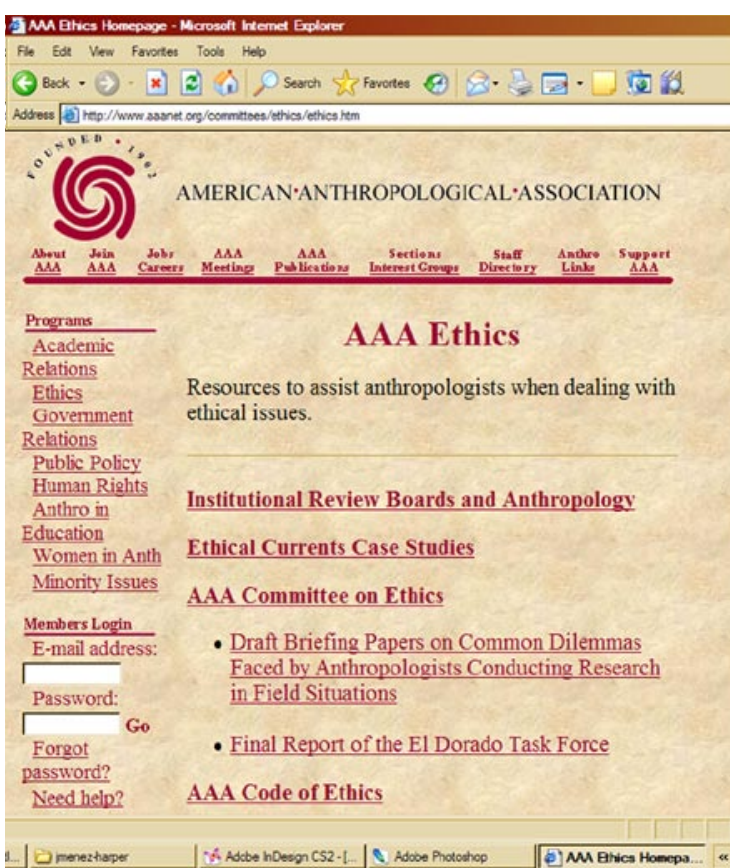

tive website where the development and evolution of our guidelines is opened up to all ASA members (www.theasa. org/ethics.htm). The site was launched with a call to debate the ethics and politics of the Pat Roberts Intelligence Scholars Program (PRISP), the subject of recent debate in the pages of ANTHROPOLOGY TODAY (AT 20[4], AT 21[35]). This issue - and the broader implications of secrecy around anthropological research, and clandestine activities - is a vital area of debate that anthropologists should be contributing to, and making ethnographically more robust.

We also hope that the site will be particularly useful to postgraduates. Too often we only acquire ethical selfconsciousness when we read about the transgressions of our seniors. However, our experience suggests that the diversity of ethical issues and dilemmas faced by postgraduate students should be a rich source of input and comments from the field; we hope this will be a site where the ethical situations that postgraduates find themselves caught in can be posted and commented upon. It is also a space which invites users to think of web resources as yet another way of offering ethical and critical thinking.

The forum will also be open to non-ASA members. In all cases submissions will be monitored to make sure they adhere to basic rules of internet etiquette. We should first and foremost facilitate the development of the ethical integrity of our profession, and explore the nature and limits of our expert knowledge (O’Neill 2002b). In order to ensure that we do not exteriorize our relationship with ethics, this engagement should be unmediated and should reflect the ethical integrity of the profession. This would turn the personal commitment of individual anthropologists and students into a source of robust knowledge and engagement. Opening up our guidelines would allow a thick engagement, or ethnographicness, a more openended and descriptive engagement with the guidelines. This 'ethnographicness' would, in short, be a part of the ethical self-description of the discipline.

This engagement should not, however, make us complacent. What looks from the inside like trust and the development of our strengths can, from another perspective, look like collusion. We still need to grapple with how anthropology deals with issues of its accountability with broader publics. But it seems more sensible to do this in conversation with those very publics, rather than behind the false closed gates of a precautionary and defensive professional autonomy. $\bullet$ 